\title{
IMPREGNERINGSPROEVEN MET VOOR DWARSLIGGERS BESTEMDE SURINAAMSE HOUTSOORTEN
}

DOOR

IR. W. SPOON

Naar aanleiding van aanbiedingen van dwarsliggers vervaardigd uit een aantal met name genoemde Surinaamse houtsoorten informeerden enige tijd geleden verschillende Nederlandse firma's in smalspoorwegmateriaal bij de Afdeling Tropische Producten van het Indisch Instituut naar de geschiktheid dier houtsoorten voor de aanbevolen bestemming.

Het betrof de loofhoutsoorten: mora (Mora excelsa Benth.), wane (Ocotea rubra Mez.), pakoeli (Platonia insignis MART.), zwarte kabbes (Diplotropis purpurea (RICH.) Амsh.), rode kabbes (Andira coriacea PULlE) en matakki (Symphonia globulifera L.).

In het bekende boekwerk ,De houtsoorten van Suriname” ${ }^{1}$ ) noemt de auteur, dr. J. Ph. Pfeiffer, in deel II, blz. 233 de volgende houtsoorten uit dat land als bruikbaar voor de vervaardiging van dwarsliggers bestemd voor een gematigd klimaat: zeer geschikt: mora, zwarte kabbes, pakoeli en wane; geschikt: rode kabbes en basralocus.

Van de houtsoorten, waarover een uitspraak werd verzocht, blijken er dus reeds vijf in de indeling volgens PfEIFFER te worden genoemd. Alleen matakki ontbreekt daarbij. Wanneer wij nu de volume-gewichten (= soortelijke gewichten luchtdroog) van de te beoordelen houtsoorten daarnaast plaatsen om een indruk van de dichtheid te krijgen, dan zien wij het volgende:

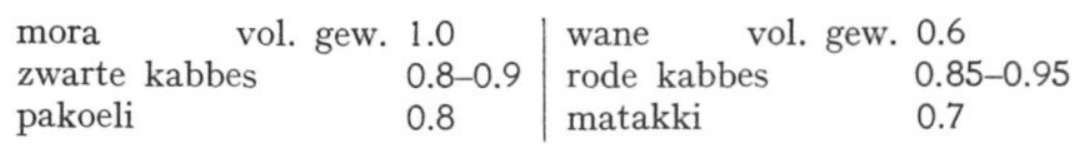

1) Meded. Afd. Trop. Producten 6 (1926/27). 
Matakki ligt dus wat dichtheid aangaat tussen de andere houtsoorten in en zou wat die eigenschap aangaat geen uitzondering voor dwarsliggers behoeven te zijn.

Praktische ervaring is bekend van mora en wane uit het gebruik ervan bij de spoorwegen in Suriname ${ }^{1}$ ) en Demarara of Brits-Guyana 2). Beide soorten dwarsliggers worden daar onbereid (d.w.z. niet geimpregneerd) gebruikt. Maar ook in Nederland beschikt men over ervaring met mora, doordat de Nederlandse Spoorwegen twee proeven er mede hebben genomen, n.l. met 180 stuks, in de baan gelegd in 1924 en met 148 stuks, gelegd in 1933 3). Van de oudste proef behoefde pas in 1946, dus na 22 jaren in de baan gelegen te hebben, de laatste 59 stuks opgeruimd te worden. En dat, terwijl de dwarsliggers in aansluiting op het gebruik in Suriname, onbereid waren gelaten. Dit resultaat bevestigt overigens het door PFEIFFER over mora geformuleerde oordeel.

Op de in de aanvang vermelde vragen konden wij dus aan de hand van literatuur en praktijkgegevens reeds vele inlichtingen verstrekken, echter niet op de vraag naar de impregneerbaarheid van de zes met name genoemde houtsoorten. En juist voor ons klimaat is de eigenschap van geimpregneerd kunnen worden in verband met de duurzaamheid zeer belangrijk. Wij hebben daarom in het laboratorium een onderzoek in die richting ingesteld.

Uit monsters van de verschillende (luchtdroge) houtsoorten zijn blokjes vervaardigd in de bekende langwerpige vorm van 5 bij $2.5 \times 1.5 \mathrm{~cm}$. De blokjes komen gedurende 30 minuten in een vacuum (gem. $20 \mathrm{~mm}$ kwikdruk) voor ontluchten en drogen, daarna wordt de voorgewarmde impregneervloeistof toegevoerd onder handhaving van het vacuum, waarna de blokjes 30 minuten in de vloeistof blijven liggen. De blokjes worden tenslotte aan de lucht bij kamertemperatuur gedroogd. Het verschil in gewicht van een blokje vóór en na de behandeling geeft de opgenomen hoeveelheid impregneermiddel aan ${ }^{4}$ ).

1) Ber. Afd. Trop. Producten 209, Dwarsliggers uit Suriname, ook verschenen in Ned. Bosbouw T. 18,33 (1946).

2) Handbook of Natural Resources of British Guiana, 108 (Georgetown 1946).

3) Meded. Afd. Trop. Producten 32, 13 (1948) (,,Inlichtingen en Onderzoekingen in 1947').

4) Verg. ook J. Eden en E. Rennerfelt in Meded. Zweedsch Bosbouwproefst. Bd. 35, 1946, gerefereerd in Tectona 37, 157 (1947). 
Enkele details van de uitvoering in ons laboratorium zijn, dat het keteltje (porceleinen bak met glazen bolvormige kap, waarin slijpstuk met verdeelkraan voor verbinding enerzijds met luchtpomp en anderzijds met reservoir met impregneervloeistof) geplaatst is in een waterbad van $90-96^{\circ} \mathrm{C}$., zodat in het toestel de temperatuur oploopt tot ongeveer $70-75^{\circ} \mathrm{C}$. De impregneervloeist of was in ons geval creosoot-olie, voorgewarmd op $60-65^{\circ} \mathrm{C}$., waarvan de Staatsmijnen in Limburg zo welwillend waren een flink monster, in de kwaliteit zoals geleverd wordt aan de Nederlandse Spoorwegen, ter beschikking te stellen (H.M. no. 5592). De samenstelling was volgens analyse van het laboratorium van de Cokesfabriek Maurits:

water

onoplosbaar in benzeen

dichtheid $38 / 15^{5}$

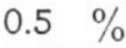

$0.5 \%$
$0.06 \%$

destillatie: tot $210^{\circ} \mathrm{C}$

1.118

$$
\begin{array}{r}
210-235 \\
235-315 \\
315-355 \\
\text { boven } 355
\end{array}
$$

coke-residu

floattest

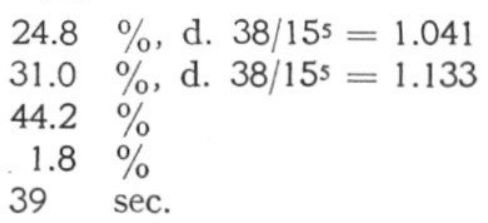

Een bezwaar bij het werken met creosoot-olie is alleen, dat het drogen van de blokjes aan de lucht tot constant gewicht zeer veel tijd vergt.

De resultaten van de zes Surinaamse houtsoorten zijn in bijgaande tabel bijeengebracht. Ter vergelijking bezigden wij drie Europese houtsoorten, die veel voor dwarsliggers worden toegepast 1), nl. grenen (Pinus silvestris L.), eiken (Quercus robur L.) en beuken (Fagus silvatica L.). Voor zover het monstermateriaal het toeliet, is van elke houtsoort spint en kern afzonderlijk onderzocht (d.w.z. bij beuken spint en rijphout).

Bezien wij eerst de drie Europese houtsoorten. Grenen vormt als enige naaldhoutsoort enigermate een uitzondering in dit gezelschap, zowel spint als kern nemen ruim creosoot-olie op. Van eiken neemt de kern veel minder olie op dan bij beuken (d.w.z. het rijphout ervan).

1) Zie b.v. Ber. Afd. Trop. Producten $I 77$, Indische dwarsliggers in Nederland, ook verschenen in Ned. Bosbouw T. 15, 89 (1942). 
De Surinaamse houtsoorten staan alle ver achter bij beuken, vooral wat de opname door het kernhout aangaat. Ten opzichte van eiken-kernhout is het verschil minder groot. Twee Surinaamse houtsoorten, nl. pakoeli en wane, nemen al heel weinig olie op, nl. 3.3 resp. $3.9 \%$ in het kernhout, bij de overige vier is dit in het kernhout wat beter (7.8 tot $9.4 \%$ ), doch nog altijd minder dan eiken (12.1\%) en veel minder dan beuken $(35.1 \%)$.

Enig verband tussen de dichtheid van het hout, beoordeeld naar het volume-gewicht, en het opnemen van creosoot-olie is niet te bespeuren, integendeel, de Surinaamse houtsoorten, hoewel in dichtheid uiteenlopende van 0.6-1.0, ontlopen elkaar in het opnemen van olie heel weinig. Want zelfs in het spinthout blijft deze opneming nog duidelijk aan de lage kant.

Amsterdam, Februari 1949. 


\section{IMPREgNATING SURINAM TIMBER}

\section{(Summary)}

Some time ago six species of Surinam timber were recommended for use as sleeper or crosstie, viz. mora, wane or determa, pakoeli or pakuri, tatabu or ,,zwarte kabbes”, kuraru or „,rode kabbes” and matakki or manni. However, no particulars were available about the impregnating capacities. Therefore in the laboratory of the Tropical Products Department of the Royal Institute for the Indies, Amsterdam, some experiments were made with creosote oil. As comparison were used the European species pine, oak and beech.

From the various kinds of timber cubes were made measuring $5 \times 2.5 \times 1.5 \mathrm{~cm}$. The impregnating was done in vacuum, after which the cubes were dried on the air. A table gives the amount of oil absorbed by the various samples, for sapwood and heartwood separately.

The Surinam species appear to absorb less oil; especially the amount of oil which penetrates the heartwood is moderate to small.

Impregnering van enige Europese en Surinaamse houtsoorten

\begin{tabular}{l|l|l|l|l}
\hline $\begin{array}{c}\text { Monster- } \\
\text { nummer }\end{array}$ & \multicolumn{1}{|c|}{ houtsoort } & \multicolumn{1}{c}{$\begin{array}{c}\text { volume- } \\
\text { gewicht }\end{array}$} & \multicolumn{2}{|c}{$\begin{array}{c}\text { opgenomen hoeveelheid } \\
\text { creosoot-olie }\end{array}$} \\
\hline T.P. 114-2 & grenen & 0.52 & spint & $90.9 \%$ \\
T.P. 103-2 & eiken & 0.67 & $\begin{array}{l}\text { kern } \\
\text { spint }\end{array}$ & 62.3 \\
kern & $50.6 \%$ \\
T.P. 103-1 & beuken & 0.72 & spint & $42.1 \%$ \\
& & & rijphout & 35.1 \\
H.M. 5522-1 & mora & 1.0 & spint & $21.4 \%$ \\
& & kern & 7.8 \\
H.M. 5522-10 & zwarte kabbes & $0.8-0.9$ & kern & $9.2 \%$ \\
H.M. 5522-8 & pakoeli & 0.8 & spint & $23.1 \%$ \\
& & & kern & 3.3 \\
H.M. 5225-4 & wane & 0.6 & kern & $3.9 \%$ \\
H.M. 5522-6 & rode kabbes & $0.85-0.95$ & spint & $24.8 \%$ \\
& & & kern & 9.4 \\
H.M. 776-M6 & matakki & 0.7 & kern & $8.6 \%$
\end{tabular}

